\title{
Intelligent e-Learning Systems: An Educational Paradigm Shift
}

\author{
S. Bhattacharya, S. Nath \\ Techno India College of Technology, West Bengal, India
}

\begin{abstract}
Learning is the long process of transforming information as well as experience into knowledge, skills, attitude and behaviors. To make up the wide gap between the demand of increasing higher education and comparatively limited resources, more and more educational institutes are looking into instructional technology. Use of online resources not only reduces the cost of education but also meet the needs of society. Intelligent e-learning has become one of the important channels to reach out to students exceeding geographic boundaries. Besides this, the characteristics of e-learning have complicated the process of education, and have brought challenges to both instructors and students. This paper will focus on the discussion of different discipline of intelligent e-learning like scaffolding based e-learning, personalized e-learning, confidence based e-learning, intelligent tutoring system, etc. to illuminate the educational paradigm shift in intelligent e-learning system.
\end{abstract}

Keywords - Confidence Based e-Learning, Intelligent e-learning system, Intelligent Tutoring System, Personalized e-Learning, Scaffolding based e-Learning, Technology Enhanced Learning and Educational paradigm shift.

\section{INTRODUCTION}

$\mathrm{E}$ -LEARNING is the computer and network-enabled transfer of skills and knowledge. Application of e-learning includes computerbased learning, web-based learning, virtual education opportunities etc. Content is provided via the Internet, audio or video tape and CDROM etc. It can be self-paced or instructor-led and it also includes various media in the form of text, image, audio, video, animation etc. It is learner centric learning mechanism irrespective of time and distance.

The Contemporary scenario of education and training is undergoing a paradigm shift under the impact of information and communication technology. The widespread uses of computers and access to the Internet have created many opportunities for online education, including improved distance-learning and classroom support. Intelligent Tutoring Systems (ITS) extend traditional computerized contentdelivery learning systems by incorporating intelligence to improve the quality of a learner's experience resulting in better achievement of learning objectives. This normally involves personalized tutoring, using factors such as learner's knowledge, emotion or learning style to alter the sequence and style of learning material.

Besides this, in conventional/classical contact mode teachinglearning process, a teacher has plenty of opportunities to facilitate a student as per his or her level of understanding. Along with this a teacher can modulate his/her training procedure according to the various responses obtained from the learners. E-learning, under normal circumstances, cannot provide a learner the privilege of teacher's timely intervention as and when a learner requires. Human tutors have the wisdom of tuning the teaching strategy to harmonize with the student's learning style and need [22]. But the facilities are hardly present in the case of e-learning environment. Therefore in an e-learning environment, the learner faces the additional challenge of retaining learning interest in the absence of a teacher and his encouragement as well as personal care.

To face these types of challenge lot of innovative methods of in e-learning have been introduced among which a major part is based on intelligent e-learning. These types of e-Learning technology help to bridge the gap and reduce the social restrictions and facilitate a learner in many ways to achieve his objective of learning a particular subject.

In this paper the paradigm shift in intelligent e-learning has been discussed. Few areas like 'Scaffolding Based e-Learning', 'Personalized e-Learning', 'Confidence Based e-Learning', 'Intelligent Tutoring System' and 'Technology Enhanced Learning are shortly discussed with recent research activates on those fields. Several works on the said area has been discussed with their limitation and motivation. The main focus of this paper is to enlighten the educational paradigm shift of intelligent e-learning system.

Rest of the paper is organized as follows. Section 2 (Some Popular Techniques Of E-Learning) that describe some common method like scaffolding based e-learning, personalized e-learning, confidence based e-learning, etc. to elaborate the paradigm shift of intelligent e-learning. Section 3 describes a comparative study on some recent research work on intelligent e-learning. Section 4 provides conclusion.

\section{Some Popular Techniques of E-Learning}

In this section some popular techniques, like scaffolding based e-learning, personalized e-learning, confidence based e-learning, intelligent tutoring system, and technology enhanced learning have been discussed in short with a few related works.

\section{A. Scaffolding based E-Learning}

The Scaffolding based E-Learning strategy provides individualized support based on the learner's zone of proximal development (ZPD). When using the scaffolding based e-learning strategy the goal of the learner is actually to become an independent and self-regulating learner and problem solver. Learners are guided and supported through learning activities that serve as interactive bridge to get them to the next level. Thus the learner develops or constructs new understandings by elaborating on their prior knowledge through the support provided by more capable instructors. The learner does not passively receive the information presented instead learner builds on prior knowledge and forms new knowledge with the help of teacher's prompting. Another advantage of scaffolding based e-learning is that it motivates the student so that they want to learn. Beside this it can minimize the level of frustration of the learner.

However, it is different to implement scaffolding based e-learning irrespective of any subject specially which are related to arts and literature. In the year 2014, Pratama and others [26] proposed a report 
on Scaffolding based e-learning domain. According to this report, there was a solution to solve non-stationary classification problems. A Generic-Classifier (g-Class), which is a kind of novel meta-cognitivebased scaffolding classifier, is proposed to solve this problem. Metacognitive learning not only focused on how-to-learn but also on whatto-learn and when-to-learn. Generic-Classifier is able to provide an encouraging numerical value which can maintain a balance between predictive accuracy and classifier's complexity. Ghazi and others [15] proposed a report on the effectiveness of Cognitive and Meta-cognitive Strategies on learning system in the year 2013. The objective was to identify the effect of cognitive and meta-cognitive strategies on learning system, which can be either self-regulated learning system or formal learning system. Some tools or techniques were used in this research work, i.e. Motivated Strategies for Learning Questionnaire (MSLQ), SPSS-16, Cross-tab and Chi-square. In 2012, Tseng and others [31], proposed a report on enhancing the interest of children reading wit e-books by scaffold participatory learning approach. Children are more interested in learning those materials are which combinations of visual and verbal narrative. This research work proposed a scaffolded participation learning model. In 2012, Sengupta and others [28] proposed a report on Scaffolding based learning that support Personalized Synchronous e-learning. One of the major advantages of web based learning systems was that it was self-paced, independent on time and distance. Besides this, it was more effective with a supportive test case session that meant synchronous tutorial session. According to this research work, automated scaffolding technique was designed to hold the important information about learner. This information used by the learner with monitor in the 'Synchronous learning Session' was to make the overall system more applicable

\section{B. Personalized e-Learning}

PLE (Personal Learning Environment) is suggested as the nextgeneration e-learning system [19].The personalization can also be a static or dynamic process, depending on when the selection and presentation of material takes place: if the material is decided once in advance, we say that the course is configured; when the material is stated at run-time, that is during the course delivery, the course is said to be adaptive.

Personalized e-Learning not only customized the learning environment, but also offered "preferences" and "settings" options, the most digital tools offer nowadays. Personalized e-learning seems to reduce learning gaps between instructor and learner. In personalized e-learning this is expected that the learning materials will be generated as per the preference of the learner. Finally the entire webpage will appear to the learner in the most confortable way to him or her. In 2015, Zhanga and others [34], proposed a system on Personalized e-learning which is based on Google Web Toolkit. In this modern age due to huge development of internet technology, information overloading may be formed. Sometimes it is difficult for user to retrieve their specific information. To solve this issue this research work proposed a personalized e-learning system with collaborative filtering recommender algorithm, based on Google Web Toolkit. So, as a result of this, recommendation of personalized information can be achieved very easily and also the learning efficiency can also be improved simultaneously. In the Google Web Toolkit the client and server use single programming language to develop web application.

In 2014, Nandigam and others [23], proposed a report on personalized learning and made a review on its current status and potential. The objective of this research work is to identify 'Acceptable Personalized, which was learning suitable for specific educators for particular learning course. This proposed report presented a coherent framework for personalized learning and used to provide 'Acceptable Personalized Learning' for specific learner. This research work used the higher education teaching and learning platform through group discussion to improve learning outcomes. In 2013, Bezza and others [3] proposed an approach for Personalizing Learning Content. This research work represented two methods for modeling learner profile and personalizing, as well as adapting a specific content to match with the particular learner profile. These two methods are inductive and deductive. The inductive method means there is no user intervention and the deductive one means there is user intervention. In 2013, Chunzhi and others [7] proposed a report on the study about e-learning system which was based on 'Personalized Knowledge Search'. This research work creates a domain to build an interest model and this model is embedded in Notch search engine to identify the personalized knowledge search. This research work proposed that, through the construction of domain ontology the personalized knowledge search could be able to increase the learner's learning interests and could be able to fulfill any requirement of individual learner according to their learning courses.

\section{Confidence Based E-Learning}

Confidence-Based Learning or CBL is a methodology used for both learning and training that measures a learner's knowledge level and quality prior to any knowledge dissemination. Measurement of knowledge is done by determining both the correctness and confidence that the learner already has. To fulfill the objective of CBL it always passes an individual learner through an assessment prior to the delivery of the content. The assessment not only identifies the learner's knowledge level but also checks out the level of confidence she has in her knowledge level. This process of assessment is known as Confidence Based Assessment (CBA). CBL is operated with the help of three different phases Diagnose, Prescribe, Learn. The Diagnose phase deals with the diagnosis of the true knowledge of learners (i.e., what they actually know vs. what they think they know.).Learner's knowledge gaps (if any) are identified through the diagnostic session and in the Prescribe session the CBL system immediately provides an individual learning plan for the learner to improve the confidence of learner. In the initial phase learner is able to start learning according to the prescribed plan. Confidence Based Learning is affordable and scalable. Confidence Based Learning is useful to upgrade individual confidence according to learning objectives. Confidence Based Learning is not suitable for vocational education. Persons new in a field might not find Confidence Based Learning as an acceptable mechanism; rather conventional mechanism might work better. In Confidence Based Learning, it is difficult to measure appropriate level of confidence in numerical value.

In 2012, Liu and others [20] proposed a report on Confidence Based Learning domain. This research work proposed a social learning with the help of constant called bounded confidence. In this research work identify that a group can learn the true state if and only if the bound of confidence is more than the positive threshold and this work also proposed a neighborhood-preserved strategy. In 2012, Ananatharman [2] proposed a system which can be able to manage knowledge and elearning. The objectives of this research work were providing a usage of e-learning and provide some facility with proper assessment for the learner. This research work discussed about various learning models such as blended learning, creative learning, interactive learning etc. In 2012, Zhang and others [33] are proposed a report on Interactive Learning for Social Agents which was based on Confidence Degree. In the Multi-Agent Systems, autonomous agents are capable to acquire cooperative behavior with the help learning process. The confidence is helpful to apply the proper knowledge in the application field. A social agent can acquire this confidence through interactive learning process. In 2011, Grozavu and others [17] proposed a report on learning confidence domain. The objective of collaborative clustering is to identify the common structure of different data which are distributed 
on various sites. This research work represents the approach for SelfOrganizing Maps.

\section{Intelligent Tutoring System}

The aim of an 'Intelligent Tutoring System' is to provide immediate and customized instruction as per the feedback of learners. Usually in this type of system the physical instructor is absent.

Intelligent tutoring system has the common goal of enabling learning in a meaningful and effective manner by using a variety of computing technologies. There are many examples of 'Intelligent Tutoring System' which are being used in both formal education and professional settings in which they have demonstrated their capabilities and limitations. An Intelligent Tutoring System aims to solve the problem of over-dependency of students on teachers for quality education. It aims to provide access to high quality education to each and every learner, thus reforming the entire education system. Areas that have used Intelligent Tutoring System include natural language processing, machine learning, planning, multi-agent systems, semantic Web, and social and emotional computing. In addition, other technologies such as multimedia, object-oriented systems, modeling, simulation, and statistics have also been connected to or combined with Intelligent Tutoring System. Some recognized strengths of Intelligent Tutoring System are their ability to provide immediate yes/ no feedback, individual task selection, on-demand hints, and support mastery learning. Intelligent Tutoring Systems are expensive both to develop and implement. Evaluation of an Intelligent Tutoring System is an important phase; however, it is often difficult, costly, and time consuming. In 2015, Elghibari and others [13] are proposed a model of intelligent e-learning system for maintenance of various updates courses. The teaching methods become more effective with the help of e-learning technology. But lack of learning course update can create some problem for learner. So it is important to maintain or update the learning course content regularly. This research work proposed a model for automatic updating and maintaining learning course content using Multi-Agent Systems.

In 2013, Otsuki and others, [24] proposed an Intelligent Tutoring System which could be able to provide a support for Case-Based e-learning for the project management. This research work encouraged the learner to think as many possible solutions on his/her own through the dialogue function between the teacher and learner. It is helpful to the learner to develop the problem solving ability. In 2012, Moore and others, [21] proposed a Personalized Intelligent e-learning for specific context on demand basis. This research work provided an overview of open research questions and some observation to enable effective personalization. This work presented an overview on the educational landscape, web 2.0 technologies, context-aware systems, intelligent context processing. It also renders an algorithm which is used for context matching. In 2013, Almohammadi and Hagras [1] proposed a system which was based on adaptive fuzzy logic and used for improving the knowledge delivery on the intelligent e-learning platforms. This research work created a self-learning system which could be able to generate a fuzzy logic based model. This model represented various learners' capabilities and their needs and through this, it had also improved the learner's performance. This work also provided an overview on artificial intelligence techniques and fuzzy logic systems on adaptive educational systems.

\section{E. Technology Enhanced Learning}

E-learning, also known as online learning or technology enhanced learning (TEL), adheres to the basic tenets of face-to-face teaching, e.g. clear aims, specific learning outcomes, valid and reliable evaluation and assessment but with an additional flexibility through the use of technology. TEL and e-learning describe the broad approach to use technology to support teaching and learning processes, design and delivery.

The use of technology can add value to learning by enhancing the information the accessibility of over a greater choice of time, place and pace of study. It is able to provide the opportunities for reflection and planning in personal learning spaces. Technology Enhanced Learning is a more active learning process by means of interactive technologies and multimedia resources. But there are some disadvantages of Technology Enhance Learning process. To deal with this Technology Enhanced Learning a person should be technology literate. Technology Enhanced Learning is expensive to develop and implement. So for this reason it is difficult to install many Technology Enhanced Learning systems due to financial problem and some environmental problem.

In 2015, Erdt and others [14] proposed a quantitative survey on evaluating recommender systems. Recommender systems Technology Enhanced Learning need specific requirements which are different from that of e-commerce. This research work highlights the strengths and the shortcomings of the evaluation of Technology Enhanced Learning. This evaluation is based on measuring recommender system performance, measuring user-centric effects, measuring effects on learning etc. In 2015, Trepule and others, [30] proposed an approach of introducing technology enhanced learning curriculum for teaching staff in higher education. The objective of this research work is to maintain a quantitative survey between teaching staff and learner, and make a statistical analysis on the basis of survey outcomes. In 2011, Ivanovic and others [18], proposed a report on experiences of Technology Enhanced Learning for various courses. This research work collected various experiences and made a comparison among those gathered bits of information. This report provided some methodologies for learning and learner's assessment. In 2011, Dagdag and others [9] proposed a teacher's tool for analysis and management of a TechnologyEnhanced Learning environment. The objective of this research work was to develop a software tools that could help the teachers to analyze technology-enhanced learning environment and with this tools teacher could be able to monitor the learner in real time, and make a proper assessment towards their progress at any time. In the year 2009 Oscar Sanjuán Martínez [35] proposed a recommendation system for e-learning environments at degree level. This recommendation Systems try to help the user, presenting him those objects he could be more interested in, based on his known preferences or on those of other users with similar characteristics. This document tries to present the current situation with regards to recommendation systems and their application on distance education over the internet. Beside that in 2014, Jordán Pascual Espada [36] proposed a method for analyzing the user experience in MOOC platforms. This research aims to develop a specific method for evaluating the user experience of MOOC platforms. The method is based on the general principles of Web user experience and highlights the aspects influencing MOOCs. The system proposed in this paper calculates a quantifiable index, useful for comparing different MOOC platforms, quantifying the quality evolution of the user experience, and promoting further studies so as to determine the impact of the user experience on students: satisfaction in surveys, enrollment figures, dropout rates, among others.

\section{Comparative Study}

In this section some recent works on intelligent e-learning are compared with their motivation and limitation. This research work is based on some of the recent works of the paradigm shift of intelligent e-learning. A review on different aspect of e-learning techniques such as Scaffolding based e-learning, Personalized E-Learning, Confidence Based E-Learning, Intelligent Tutoring System, Technology Enhanced Learning are presented in the table 1. 
Table I. Comparative Study Report

\begin{tabular}{|c|c|c|c|}
\hline Sl. No. & Reference No. & Summary & Limitation \\
\hline 1 & 11 & $\begin{array}{l}\text { This paper represented a new approach to the integration of web services for } \\
\text { e-learning platform through cloud computing system. The primary objective } \\
\text { was to improve the performance of the e-learning system where group } \\
\text { adaptation was applied. This integration was based on a web application } \\
\text { which was developed for managing the various learning systems. Integration } \\
\text { of the Moodle was enables between the OpenLDAP directory which was used } \\
\text { to control various user accounts, and the OpenNebula toolkit which was used } \\
\text { for managing a cloud computing infrastructure. }\end{array}$ & $\begin{array}{l}\text { One of the main limitations of this proposed } \\
\text { approach is, this research work is based on } \\
\text { group personalization and it does not provide } \\
\text { support to any kind of real time adaptation. This } \\
\text { approach is prepared for courses which require } \\
\text { extensive usage of various hardware and also } \\
\text { software resources and it may not be suitable for } \\
\text { courses, having different requirements. }\end{array}$ \\
\hline 4 & 10 & $\begin{array}{l}\text { This research work proposed a comprehensive framework which could be } \\
\text { able to provide support to the personalization and also helps in adaptation of } \\
\text { e-learning courses. The objective of this comprehensive framework was to get } \\
\text { its pedagogical significance by the Vygotski Theory. }\end{array}$ & $\begin{array}{l}\text { In the real world environments it is not able } \\
\text { to provide real time framework for each } \\
\text { individual's educational activities. }\end{array}$ \\
\hline 5 & 5 & $\begin{array}{l}\text { This research work represented CobLE (Confidence-Based Learning } \\
\text { Ensembles), and CobLE is one kind of approach for creating an ensemble } \\
\text { of classifiers and each and every classifier is estimated by measuring its } \\
\text { confidence level function. }\end{array}$ & $\begin{array}{l}\text { In the real world environments it is very } \\
\text { difficult to estimate proper confidence level } \\
\text { function. }\end{array}$ \\
\hline 6 & 4 & $\begin{array}{l}\text { This research work represented a platform which was able to provide an } \\
\text { interface to e-learner under the online web based e-learning domain. On } \\
\text { the basis of the concept map trees, it was possible to intelligently identify } \\
\text { the learning pattern of an individual e-learner. It helped the learner to attain } \\
\text { learning objectives through the various recommender agents. }\end{array}$ & $\begin{array}{l}\text { This research work offers an environment } \\
\text { based on personalized e-learning with the help } \\
\text { of different access patterns. But in the real } \\
\text { world environment it is very difficult by the } \\
\text { recommender agent to recognize various learning } \\
\text { pattern for the different kind of e-learner. }\end{array}$ \\
\hline 8 & 27 & $\begin{array}{l}\text { This research work represented an intelligent fuzzy evaluation system which } \\
\text { was based on innovative evaluation method for e-learning. This paper also } \\
\text { introduced an expert system which could be able to provide solutions to the } \\
\text { 'Measurement Theory Problem'. }\end{array}$ & $\begin{array}{l}\text { In the real world sometimes it is not possible } \\
\text { to provide absolutely correct and specific } \\
\text { evaluation for e-learning. }\end{array}$ \\
\hline 9 & 6 & $\begin{array}{l}\text { This research work concentrated at the learning possibilities of the integrating } \\
\text { social media and web } 2.0 \text { technologies in a Problem-Based Learning (PBL) } \\
\text { approach. This research work proposed that social media not only provide a very } \\
\text { interesting perspective, and also look at various factors such as collaboration, } \\
\text { different student activity and participation in problem-based learning. }\end{array}$ & \\
\hline 10 & 12 & $\begin{array}{l}\text { In the proposed system, various learners shared their resource with their } \\
\text { friends in the online social network. The similarity between two friends was } \\
\text { derived from their mutual rating's history. A learner could ask his friend } \\
\text { various resource rating query through the online social network and could also } \\
\text { solve the problem. }\end{array}$ & $\begin{array}{l}\text { In the real environment it is very cost effective } \\
\text { and this type of system is applicable for those } \\
\text { people who are modern technology friendly. }\end{array}$ \\
\hline 11 & 29 & $\begin{array}{l}\text { This paper proposed an 'Intelligent Decision Supporting Tutor (IDST)' } \\
\text { system for the management of Virtual Group Operation' of e-learning system. } \\
\text { Interactive Tutor Robot Networking (ITRN) and advanced simulation } \\
\text { technology were also implemented by this research work. According to } \\
\text { this paper, Intelligent Decision Supporting Tutor had two different kinds of } \\
\text { knowledge based engines, the first one was the database of knowledge which } \\
\text { was present in cloud computing server and the second one was used to make } \\
\text { a fusion of human brains which was again constructed by Interactive Tutor } \\
\text { Robot Networking. }\end{array}$ & $\begin{array}{l}\text { To design this type of system in real world is } \\
\text { time consuming and costly. }\end{array}$ \\
\hline
\end{tabular}


IV. CONCLUSION

The objective of this research work is to elaborate the paradigm shift in intelligent e-learning system. In this paper various details of different e-learning techniques are included. A discussion about advantages and disadvantages of these techniques and a review on the basis of recent work of this intelligent e-learning domain like Scaffolding based E-Learning, personalized e-learning, confidence based e-Learning, intelligent system, technology enhanced learning etc, are included in this paper. In the e-learning domain intelligent learning technology facilitates a learner in many ways to achieve his objective of learning a particular subject. Scaffolding based e-learning motivates the students so that they want to learn, which in turn, can minimize the level of frustration of the learner. Confidence based learning is useful to upgrade individual confidence. The strengths of intelligent tutoring system are their ability to provide immediate yes/ no feedback, individual task selection, on-demand hints, and support mastery learning. Disadvantage of e-learning domain is lacks of standardization and it needs computer literacy.

\section{REFERENCES}

[1] Almohammadi, K. and Hagras, H., 2013, July. An adaptive fuzzy logic based system for improved knowledge delivery within intelligent E-Learning platforms. In Fuzzy Systems (FUZZ), 2013 IEEE International Conference pp. 1-8.

[2] Ananatharman L. Knowledge management and learning: ELearning and knowledge management system. InInteractive Collaborative Learning (ICL), 2012 15th International Conference on 2012 Sep 26 pp. 1-6.

[3] Bezza A, Balla A, Marir F. An approach for personalizing learning content in e-learning systems: A review. Ine-Learning and e-Technologies in Education (ICEEE), 2013 Second International Conference on 2013 Sep 23. pp. 218-223.

[4] Bhattacharya S, Basu P, Chakraborty A, Roy S. A framework for interactive pattern based adaptive recommender agent using concept map for personalized e-learning: IPBARA. InTechnology Enhanced Education (ICTEE), 2012 IEEE International Conference on 2012 Jan 3 .pp. 1-5.

[5] Buthpitiya S, Dey AK, Griss M. CobLE: Confidence-Based Learning Ensembles. InComputational Science and Computational Intelligence (CSCI), 2014 International Conference on 2014 Mar 10 Vol. 1, pp. 386391.

[6] Buus L. Scaffolding Teachers Integrate Social Media into a ProblemBased Learning Approach? Electronic Journal of e-Learning. 2012; Vol: 10(1).pp13-22.

[7] Chunzhi W. Study of the E-learning system based on the personalized knowledge search. InComputer Science \& Education (ICCSE), 2013 8th International Conference on 2013 Apr 26 pp. 592-598.

[8] Dabbagh N, Kitsantas A. Personal Learning Environments, social media, and self-regulated learning: A natural formula for connecting formal and informal learning. The Internet and higher education. 2012 Jan 31; Vol: 15(1).pp3-8.

[9] Dagdag RJ, Mariano RV, Atienza RO. Teacher tool for visualization and management of a technology-enhanced learning environment. InTENCON 2011-2011 IEEE Region 10 Conference 2011 Nov 21 pp. 1426-1430.

[10] De Marsico M, Sterbini A, Temperini M. A framework to support socialcollaborative personalized e-learning. InInternational Conference on Human-Computer Interaction 2013 Jul 21 (pp. 351-360). Springer Berlin Heidelberg.

[11] Despotović-Zrakić M, Simić K, Labus A, Milić A, Jovanić B. Scaffolding Environment for e-Learning through Cloud Computing. Educ. Technol. Soc. 2013;Vol:16(3).pp301-14.

[12] Dwivedi P, Bharadwaj KK. E-learning recommender system for learners in online social networks through association retrieval. InProceedings of the CUBE International Information Technology Conference 2012 Sep 3. pp. 676-681.

[13] Elghibari F, Elouahbi R, Elkhoukhi F, Chehbi S, Kamsa I. Intelligent e-learning system model for maintenance of updates courses. InInformation Technology Based Higher Education and Training (ITHET), 2015
International Conference on 2015 Jun 11. pp. 1-3.

[14] Erdt M, Fernández A, Rensing C. Evaluating Recommender Systems for Technology Enhanced Learning: A Quantitative Survey. IEEE Transactions on Learning Technologies. 2015 Oct 1. Vol.: 8(4).pp. 326-44.

[15] Ghazi, S. R., Gilani, U. S. \& Fatima, Z. T. (2013), "Effectiveness of Cognitive and Metacognitive Strategies in Scaffolding based SelfRegulated Learning

[16] System and Formal Learning System", International Journal of Academic Research in Progressive Education and Development, Vol. 2, No. 3, pp.97 -104 .

[17] Grozavu N, Ghassany M, Bennani Y. Learning confidence exchange in collaborative clustering. InNeural Networks (IJCNN). The 2011 International Joint Conference on 2011 Jul 31. pp. 872-879.

[18] Ivanović M, Komlenov Ž, Xinogalos S. Technology enhanced learning for programming courses-Experiences and comparison. InInteractive Collaborative Learning (ICL), 2011 14th International Conference on 2011 Sep 21. pp. 42-45.

[19] Kolås, L., and A. Staupe. "A requirement specification of a next generation e-learning system."

[20] Liu Q, Wang X. Social learning with bounded confidence. InIntelligent Control and Automation (WCICA), 2012 10th World Congress on 2012 Jul 6. pp. 3485-3490.

[21] Moore P, Pham HV. Personalized Intelligent Context-Aware E-Learning on Demand. InComplex, Intelligent and Software Intensive Systems (CISIS), 2012 Sixth International Conference on 2012 Jul 4 pp. 965-970.

[22] Goyal M, Yadav D, Tripathi A. Fuzzy approach to detect learning style using McCarthy model as a tool for e-learning system. InEmerging Trends and Technologies in Libraries and Information Services (ETTLIS), 2015 4th International Symposium on 2015 Jan 6. pp. 295-300.

[23] Nandigam D, Tirumala SS, Baghaei N. Personalized learning: current status and potential. Ine-Learning, e-Management and e-Services (IC3e), 2014 IEEE Conference on 2014 Dec 10. pp. 111-116.

[24] Otsuki M, Samejima M. An Intelligent Tutoring System for CaseBased E-Learning on Project Management. In2013 IEEE International Conference on Systems, Man, and Cybernetics 2013 Oct 13. pp. 34713476.

[25] Ouf S, Nasr M, Helmy Y. An enhanced e-learning ecosystem based on an integration between cloud computing and Web2. 0. InThe 10th IEEE International Symposium on Signal Processing and Information Technology 2010 Dec 15. pp. 48-55.

[26] Pratama M, Er MJ, Anavatti SG, Lughofer E, Wang N, Arifin I. A novel meta-cognitive-based scaffolding classifier to sequential non-stationary classification problems. In2014 IEEE International Conference on Fuzzy Systems (FUZZ-IEEE) 2014 Jul 6. pp. 369-376.

[27] Salmi K, Magrez H, Ziyyat A. A fuzzy expert system in evaluation for E-learning. In2014 Third IEEE International Colloquium in Information Science and Technology (CIST) 2014 Oct 20. pp. 225-229.

[28] Sengupta S, Mukherjee B, Bhattacharya S. Designing a scaffolding for supporting personalized synchronous e-learning. Department of Computer Science \& Information Technology, Bengal Institute of Technology, Kolkata-150, India. 2012.

[29] Tojo T, Noh NM, Ono O, Yusof R. Intelligent decision supporting tutor in virtual group operation control and management based on e-learning system. InControl Conference (ASCC), 2015 10th Asian 2015 May 31. pp. 1-6.

[30] Trepule E, Tereseviciene M, Rutkiene A. Didactic Approach of Introducing Technology Enhanced Learning (TEL) Curriculum in Higher Education. Procedia-Social and Behavioral Sciences. 2015 Jun 2; Vol. 191. pp. 84852.

[31] Tseng KH, Liu CC, Liu BJ. Scaffolded participatory and collaborative learning: Enhancing children reading with E-book readers. InWireless, Mobile and Ubiquitous Technology in Education (WMUTE), 2012 IEEE Seventh International Conference on 2012 Mar 27. pp. 142-146.

[32] Wan AT. Influencing Factors in Using Interactive E-Learning Tool. Open Journal of Social Sciences. 2016 Feb 22; Vol.4 (02). pp. 211.

[33] Zhang K, Maeda Y, Takahashi Y. Interactive learning of social agents based on confidence degree. InFuzzy Systems (FUZZ-IEEE), 2012 IEEE International Conference on 2012 Jun 10. pp. 1-4.

[34] Zhanga, Ye Jun, and Bo Songb. "A Personalized e-Learning System Based on GWT.” (2015): pp. 183-187. 
[35] Sanjuan-Martinez O, G-Bustelo BC, Crespo RG, Franco ET. Using Recommendation System for E-learning Environments at degree level. International Journal of Interactive Multimedia and Artificial Intelligence. 2009 Dec;1(2).

[36] Espada JP, Rodríguez CC, García-Díaz V, Crespo RG. Method for analysing the user experience in MOOC platforms. InComputers in Education (SIIE), 2014 International Symposium on 2014 Nov 12 (pp. 157-162).

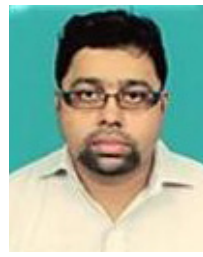

Suman Bhattacharya. He has obtained Bachelor of Engineering (I.T.) in 2004 (MCKV Inst. of Eng., West Bengal, INDIA), M.Tech (Comuter Sc and application) in 2010 (University of Calcutta, West Bengal, INDIA) and Ph.D. (pursuing) (University of Calcutta, West Bengal, INDIA). Currently is working as Asst. Professor in the department of Information Technology, Kolkata, West Bengal, INDIA.

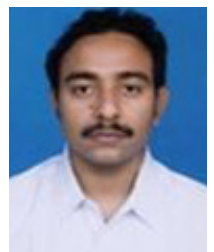

Sayan Nath. He has obtained Bachelor of Technology (C.S.E) in 2009 (B.P.Poddar Institute of Management and Technology., West Bengal, INDIA), M.Tech (Multimedia \& Software System) in 2014 (West Bengal University Of Technology, West Bengal, INDIA). Currently is working as Asst. Professor in the department of Information Technology, Kolkata, West Bengal, INDIA. 